\title{
PrevalênCIA de TraÇO FAlCIFORME EM INDIVÍDUOS ASSINTOMÁTICOS DA CIDADE DE ARARAQUARA
}

Bruno Rocha de Jesus*

Heloise Brait Rino*

Elza Regina Manzolli Leite**

Amauri Antiquera Leite***

Miriane da Costa Gileno****

\section{Resumo:}

A anemia falciformeé umahemoglobinopatia genética, caracterizada por uma alteração na estrutura da molécula de hemoglobina ( $\mathrm{HbA1}$ ), denominada hemoglobina $\mathrm{S}(\mathrm{HbS})$, que provoca uma distorção da estrutura dos eritrócitos, passando de forma esférica para forma de "foice" (sicke-cell). Este fenômenoéconhecido como falcizaçãoe éresponsável por um quadro de anemia grave em indivíduos homozigotos e por quadros esporádicos de dor em indivíduos heterozigotos (portadores de traço falciforme), de acordo com a patofisiologia, em situações de baixa concentração de oxigênio. O teste mais específico e mais sensível usado para diagnosticar anemia é o teste eletroforese de hemoglobina, que é, contudo, difícil de ser incorporado em laboratórios de rotina, devido ao seu alto custo. Oobjetivo deste trabalho foi estimar a prevalência do traço falciforme na população da cidade de Araraquara-São Paulo. A prevalência de indivíduos assintomáticos com hemoglobina S (traço falciforme) na região de Araraquara-SPfoi de 1,5\%. Separandose o estudo de prevalência por raça, observamos $0,6 \%$ de traço falciformeem indivíduos da raça branca e 15,4\% em indivíduos da raça negra.

*Biomédicos formados pelo Centro Universitário de Araraquara - Uniara.

**Farmacêutica-Bioquímica, Mestre em Análises Clínicas (FCF UNESP), responsável pelo setor de Imuno-hematologia do Hemonúcleo da UNESP de Araraquara, professora dos Cursos de Especialização em Hematologia e Hemoterapia - Barão de Mauá.

***Mestre e Doutor em Farmácia Clínica do Curso de Farmácia-Bioquímica - UNESP, Análises Clínicas (FCF USP), professor de Hematologia vice-coordenador do Centro de Referência Diagnósticas - NACUNESP.

****Mestre e Doutora em Análises Clínicas (FCF UNESP), professora de Hematologia Clínica e Bioquímica e Enzimologia Clínica - Uniara e professora de Hematologia Clínica nos Cursos de Especialização em Análises Clínicas e Hematologia e Hemoterapia - Barão de Mauá. 
Palavras-chave: Anemia, Hemoglobinas, Falciforme, Falcização, Solubilidade.

\section{Introdução}

O eritrócito é um dos elementos mais especializado do sangue, não possui núcleo e poucas organelas citoplasmáticas. Sua estrutura consiste de uma membrana circundando uma solução de proteínas e eletrólitos.

Mais de 95\% da proteína citoplasmática é a hemoglobina, o restante inclui aquelas enzimas necessárias para a produção de energia para a manutenção da hemoglobina num estado funcional reduzido (LEE, 1998). Uma importante propriedade da hemoglobinaé sua ligação fraca ereversível com o oxigênio, que, ligando-se prontamente à hemoglobina nos pulmões, é transportado como oxi-hemoglobina no sangue arterial e dissocia-se prontamente da hemoglobina nos tecidos. No sangue venoso, a hemoglobina liga-se aos íons hidrogênio produzido pelo metabolismo celular, tamponando o excesso de ácido (LEE, 1998).

"A hemoglobina é uma molécula globular, formada por quatro cadeias de globina que constituem dois pares: um par de cadeiaso-símiles e um par de cadeias $\beta$ símiles" (ZAGO, FALCÃO, PASQUINI, 2001). Está presente desde o início do período embrionário, sendo diferenciada ao longo da vida em síntese de cadeias, concentração e especificidade tecidual (HEMOGLOBINOPATIAS, 2008). Asíntese das cadeias de globina que constituem as hemoglobinas é expressa por genes estruturais responsáveis pela seqüência que as constituem e por genes reguladores responsáveis pela síntese quantitativa das cadeias formadas. As patologias decorrentes de alterações nos genes estruturais, as hemoglobinopatias, são caracterizadas pelo aparecimento de hemoglobinas variantes. As mutações mais comuns são pontuais e atingem a superfície externa da hemoglobina, normalmente na cadeia de globina beta, com troca de aminoácido na estrutura primária (BERTHOLO, 2001).

A anemia falciformeé uma hemoglobinopatia genética, caracterizada por uma alteração na estrutura da molécula de hemoglobina $\mathrm{A} 1$ (HbA1), pela substituição, na posição 6 da cadeia beta de globina, do ácido glutâmico pela valina, passando a ser denominada hemoglobina $\mathrm{S}(\mathrm{HbS})$, que provoca a distorção da morfologia dos eritrócitos, passando de forma esférica bicôncava para a formade "foice"(sickle-cell), fenômeno da falcização, quando expostas à queda da tensão de oxigênio e acidez metabólica (CASTRO, 2000; ZAGO, 2001; FALCÃO, 2001; PASQUINI, 2001; BRASIL, 2006).

Todas as hemácias contendo $\mathrm{HbS}$ podem adquirir a forma falciforme após desoxigenação, processo reversível após reoxigenação. No entanto, a repetição desse fenômeno provoca considerável lesão da membrana dos eritrócitos suscetíveis, fazendo com que a falcização seja irreversível, mesmo após a reoxigenação. Em decorrência da rigidez, as hemácias falcizadas irreversíveis têm uma vida média reduzida, o que contribui

REVISTA UNIARA, $n .^{0} 21 / 22,2008 / 2009$ para a anemia hemolítica dos pacientes (ZAGO; FALCÃO; PASQUINI, 2001).

O quadro clínico da anemia falciforme, diferente das anemias hemolíticas, não depende apenas dos sintomas de anemia propriamente, mas sim da ocorrência de lesões teciduais causadas nas chamadas "crises de falcização".

A hereditariedade do gene falcêmico é de caráter recessivo. A hemoglobina A, normal, possui duas cadeias $\alpha$ e duas cadeias $B$; para cada tipo existem dois genes. A mutação ocorre apenas na cadeia $\beta$, no qual os heterozigotos (HbAS) herdam apenas um gene, $\mathrm{o}$ traço falcêmico. Os eritrócitos dos heterozigotos sintetizam tanto cadeias $B$ normais e $\beta^{\mathrm{s}}$, logo possuem hemoglobina $\mathrm{A}_{1}$ e hemoglobina $\mathrm{S}$, sendo portadores assintomáticos (CASTRO, 2000). Os homozigotos (HbSS) herdam os dois genes para cadeia $\beta^{\mathrm{s}}$, sintetizando apenas hemoglobina $\mathrm{S}$, sendo portadores da doença falciforme com grave sintomatologia (CASTRO, 2000).

No Brasil, as anemias hemolíticas, como a falciforme, são de grande importância à saúde pública, em decorrência da composição étnica da população brasileira, levando a uma significativa incidência de homozigotos portadores de anemia hemolítica crônica. (BRASIL, 2006).

A hemoglobina S teve origem no continente africano (Teoria Malárica) e foi inserida no Brasil a partir de 1530, quando negros africanos escravizados eram comercializados. $\mathrm{O}$ gene da $\mathrm{HbS}$ predominou em áreas endêmicas para a malária, em especial as da África Equatorial, associado a alta prevalência do traço falciforme entre os negros africanos, e em menor escala, no Mediterrâneo, principalmente Grécia, Itália, Israel, assim como na Arábia Saudita e Índia (GRIFFTHS, 2002). Todo ser humano é suscetível à malária, mas existem características individuais que podem levar a uma resistência natural à doença, entre elas a anemia falciforme. Apesar de no Brasil a malária e a anemia falciforme não serem coincidentes, a região Amazônica é responsável por 99,6\% dos casos de malária no país, e possui a menor freqüência de hemoglobinopatias (BRASIL, 1999).

NosEstados Unidos, o traço falciforme afeta $8 \%$ da população da raça negra e o número de recém nascidos portadores da forma grave (HbSS) nesta população está estimada em 1/625 (GRIFFTHS, 2002).

\section{Objetivos}

Determinar a prevalência de indivíduos com traço falciforme na cidade de Araraquara-SP, na maioria dos casos, assintomáticos.

\section{Material e métodos}

Universo e indivíduos da pesquisa

Foram coletados $5 \mathrm{mLde}$ sangue total colhido por punção venosa, com K2-EDTA
Prevalência de traço falciforme... 
utilizando seringa e agulha descartáveis, de 200 indivíduos da cidade de Araraquara, no Laboratório de Bioquímica Clínica e Enzimologia Clínica do Centro Universitário de Araraquara - Uniara - Unidade II. As amostras foram mantidas em geladeira $\left(4^{0} \mathrm{a}\right.$ $8^{0} \mathrm{C}$ ) até a realização do teste, que ocorreu no máximo em três dias.

Os sujeitos destinados à pesquisa da HbS pela técnica de Solubilidade em microplaca foram de ambos os sexos e com idade variando de 18 a 65 anos.

\section{Teste de solubilidade - adaptado para microplaca}

Princípio do teste: A hemoglobina $S$ é insolúvel em uma solução com baixa tensão de oxigênio, esta insolubilidade cria uma alo central quando a solução contendo o sangue hemolisado é adicionada sobre um papel de filtro e também não permite a visualização de linha por detrás da microplaca devido a sua turbidez, o contrário ocorre com amostras normais (PENTEADO;LEITE, 2001).

\section{Técnica}

A microplaca foi identificada com o número dos pacientes de forma crescente horizontalmente da esquerda para a direita, reservando os dois últimos poços para os controles positivos. Em seguida dissolveu-se ditionito de sódio (NaSO2) em tampão difosfato saponina $(0,1 \mathrm{~g} / 10 \mathrm{~mL})$ e foram dispensados $200 \mu \mathrm{L}$ desta mistura (tampão/ditionito) em cada poço da microplaca. A seguir, pipetou-se $5 \mu \mathrm{L}$ do sangue a ser testado em cada poço, homogeneizando. Aguardou-se 10 minutos.

A leitura do teste foi realizada de duas formas:

1. Colocando-se a microplaca sobre um papel contendo uma linha negra:

- Teste positivo: a linha negra não foi vista por causa da insolubilidade da hemoglobina (AS).

- Teste negativo: observou-se a linha através da solução.

2. Pipetando-se, com pipeta multicanal, $5 \mu \mathrm{L}$ da reação da microplaca, que foram dispensados em papel de filtro (MAGALHÃES; ARASHIRO, 1977).

- Teste positivo: as hemoglobinas insolúveis se depositarão formando um halo semelhante a um alvo (AS)

- Teste negativo: difusão da hemólise pelo papel, sem formação de halo.

\section{Resultados}

No estudo de prevalência de Hemoglobina S na região de Araraquara-SP, das 200 amostras coletadas, 150 (75\%) eram do sexo feminino e 50 (25\%) do sexo masculino. Com relação à cor da pele, 178 (89\%) eram brancos, $9(4,5 \%)$ pardos e $13(6,5 \%)$ negros.

Utilizando o Teste de Solubilidade, foram detectadas 3 amostras positivas, resultando em 1,5\% de prevalência de $\mathrm{HbS}$ na cidade estudada (Figura 1). Destas 3 pessoas, $2(15,4 \%)$ eram da raça negra e 1 pessoa $(0,6 \%)$ era branca (Figuras 2 ,

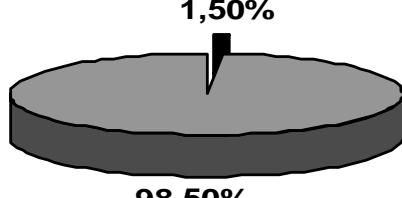

$98,50 \%$

Hemoglobina

$\square$ Hemoglobina

Normal

Figura 1. Prevalência de Hemoglobina S na cidade de Araraquara - SP sem distinção de raça.

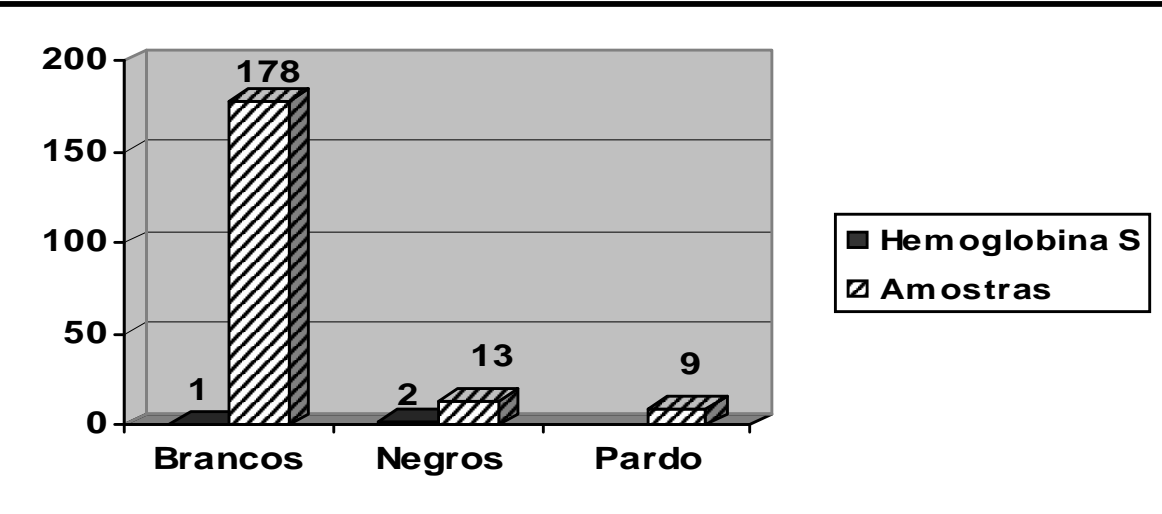

Figura 2. Relação entre as 200 amostras, cor da pele e hemoglobina S.

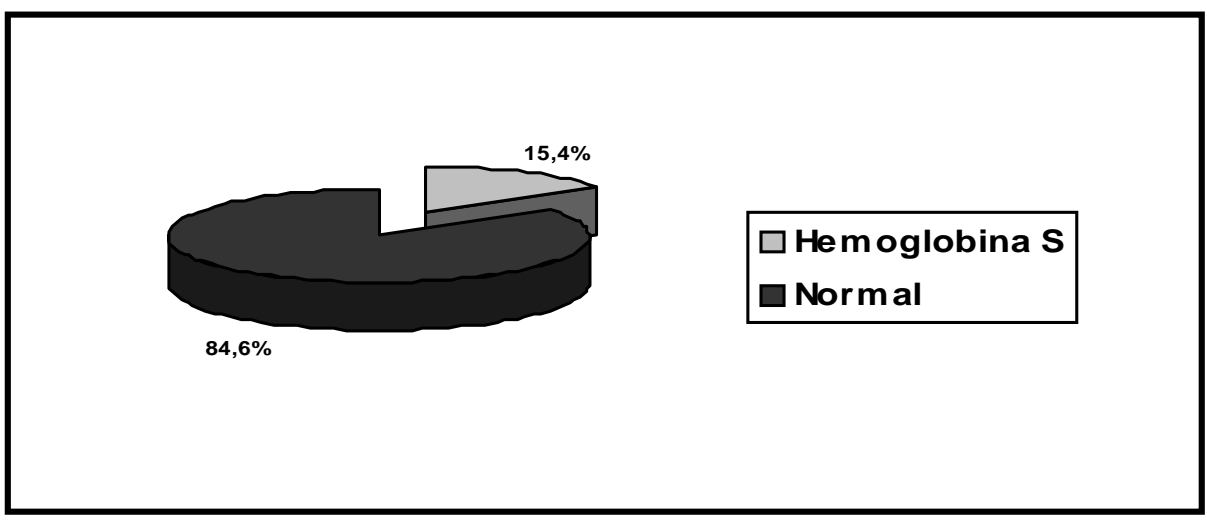

Figura 3. Prevalência de Hemoglobina S nos indivíduos negros estudados. 


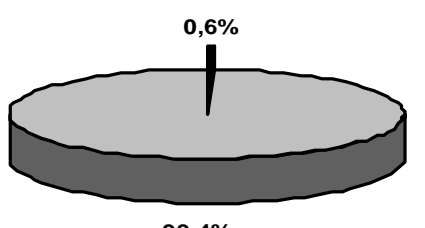

$99,4 \%$
Hem oglobina S

$\square$ Normal

Figura 4. Prevalência de Hemoglobina S nos indivíduos brancos estudados.

\section{Discussão e conclusão}

De acordo com o Ministério da Saúde, no Brasil, a frequiência de portadores de traço falciforme assintomáticos é de 2 a $8 \%$, caracterizando 3.500 nascimentos por ano para a doença falciforme e 200.000 nascimentos de indivíduos portadores de traço falcêmico.

Em nosso estudo encontramos uma prevalência de 1,5\% para traço falciforme, sendo esta, significativa para a região já que em estudos realizados anteriormente na cidade de Araçatuba-SP a prevalência encontrada foi de 1,9\% para traço falciforme (PRUDÊNCIO, 2000). Levando em consideração a localização geográfica das duas cidades, podemos analisar a característica da população de acordo com a colonização, já que ambas receberam negros vindos da África no período de escravidão para realização de várias tarefas, inclusive a predominante na região, a cultura de café, resultando em uma significativa mistura racial influenciando na dispersão de genes da doença falciforme.

Quando analisamos separadamente a relação entre a raça e a prevalência de $\mathrm{HbS}$, observamos que esta foi de $15,4 \%$ para indivíduos da raça negra, resultados semelhantes, na verdade até um pouco mais baixos (8\%), são descritos para a população Norte-Americana (GRIFFTHS, 2002).

A importância da detecção de traço falciforme em indivíduos assintomáticos permite a avaliação do risco de casais heterozigotos (AS) gerarem descendentes de caráter recessivo (SS), portadores da doença falciforme com toda sintomatologia da anemia hemolítica crônica. Também servindo de orientação ao portador, já que várias profissões ou até mesmo esportes, aumentam o fator de risco, baixa tensão de $\mathrm{O} 2$, para crises de falcização, inclusive após anestesias, onde o organismo entra em metabolismo basal, baixando níveis de oxigênio.

O diagnóstico da $\mathrm{HbS}$ também é muito importante para os bancos de sangue onde, diante desta prevalência, a chance de encontrarmos doadores com traço falciforme é grande, o que diminuiria a eficácia da transfusão já que o tempo de vida das hemácias é mais curto e poderia provocar hemólise intravascular no receptor, sendo assim a transfusão sangüínea ineficiente (PRUDÊNCIO, 2000).

\section{Referências bibliográficas:}

BERTHOLO, Luciane C. A focalização isoelétrica como diagnóstico laboratorial das hemoglobinas variantes e das talassemias na população brasileira. Araraquara: UNESP, 2001

BRASIL, Ministério da Saúde. Avaliação epidemiológica da Malária no Brasil. Brasília: Fundação Nacional de Saúde, 1999.

BRASIL, Ministério da Saúde. Manual de Condutas Básicas na Doença Falciforme. Brasília: MS, 2006.

CASTRO, Elisabeth de Carvalho et al. Anemia Falciforme. Porto Alegre: Fundação Faculdade Federal de Ciências Médicas de Porto Alegre, 2000.

GRIFFTHS, Anthony J.F. Introdução à genética. 7.ed. Rio de Janeiro: Guanabara Koogan, 2002.

HEMOGLOBINOPATIAS. Fases de desenvolvimento ontogênico das hemoglobinas. Disponível em: www.hemoglobinopatias.com.br. Acesso em: 21. jun. 2008.

LEE, G. Richard et al. Wintrobe hematologia clínica. Rio de Janeiro: Manoel, 1998. v.1.

MAGALHÃES, E.; ARASHIRO, D.N. Um método simples para visualização da hemoglobina $\mathrm{S}$ em testes de solubilidade. Revista Brasileira Patologia Clínica, n.13.p.133-34, 1977.

PENTEADO, Flora C.L.; LEITE, Amauri A. Padronização do método de solubilidade de hemoglobina $\mathrm{S}$ em microplaca. Revista de Ciências Farmacêuticas, v.22, n.2, p.239-249, 2001. 
PRUDÊNCIO, Brígida C. A. B et al. Comparação de metodologia utilizada para a deteç̧ão de Hemoglobina $\mathrm{S}$ ( $\mathrm{Hb} \mathrm{S}$ ) em doadores de sangue. Revista

Brasileira de Hematologia e hemoterapia. n.22., p.99-109, 2000.

ZAGO, Marco Antonio; FALCÃO, Roberto Passetto; PASQUINI, Ricardo. Hematologia: Fundamentos e Prática. São Paulo: Ateneu, 2001.

\section{Title:}

PREVALENCE OF HAEMOGLOBINE S IN ARARAQUARA-SP POPULATION.

\section{Abstract:}

The Sickle Cell Anemia is a genetic hemoglobionopathy, characterized by an alteration in the hemoglobin molecule struture (HbAl), called hemoglobin $S$ $(H b S)$, which causes a distortion in the erythocytes structure, changing from spherical shape to sickle shape (sickle-cell), a sickling phenomenon, which leads to severe anemia in homozygous, while sickle cell trait (heterozygote) leads to pain crisis, according to pathophysiology, in low O2 blood pressure situations. The most specific and sensitive test used to diagnose this anemia is the hemoglobin eletrophoresis test, which is, however, hard to be incorporated in routine laboratories, due to its high cost. The objective of this work was to estimate the sickle cell trait prevalence in Araraquara - SP population. The prevalence of asymptomatic individuals with the sickle cell trait was $1.5 \%$. Considering the study of race prevalence, $0,6 \%$ of sickle cell trait in white individuals and $15,4 \%$ in black ones were found.

Keywords: Anemia, Hemoglobin, Sickle Cell, Sickling, Solubility. 